\section{Limitations of the study}

There could have been some selection bias, insofar as we studied people attending a mental health service. High rates of PTSD presentation were the core feature of this population. Also, the MINI scale was used to measure PTSD, whereas a more culturally appropriate PTSD scale might have yielded different results.

\section{References}

De Jong, J., Scholte, W., Koeter, M., et al (2000) The prevalence of mental health problems in Rwandan and Burundese refugee camps. Acta Psychiatrica Scandinavica, 102, 171-177.

Gernaat, H. B., Malwand, A. D., Laban, C. J., et al (2002) Many psychiatric disorders in Afghan refugees with residential status in Drenthe, especially depressive disorder and post-traumatic stress disorder. Nederlands Tijdschrift voor Geneeskunde, 146, 11271131.
Mghir, R. \& Raskin, A. (1999) The psychological effects of the war in Afghanistan on young Afghan refugees from different ethnic backgrounds. International Journal of Social Psychiatry, 45, 29-36; discussion 36-40.

Mghir, R., Freed, W., Raskin, A., et al (1995) Depression and posttraumatic stress disorder among a community sample of adolescent and young adult Afghan refugees. Journal of Nervous and Mental Disease, 183, 24-30.

Scholte, W. F., Olff, M., Ventevogel, P., et al (2004) Mental health symptoms following war and repression in eastern Afghanistan. JAMA, 292, 585-593.

Sheehan, D. V., Lecrubier, Y., Sheehan, K. H., et al (1998) Mini International Neuropsychiatric Interview (M.I.N.I.): the development and validation of a structured diagnostic psychiatric interview for DSM-IV and ICD-10. Journal of Clinical Psychiatry, 59 (suppl. 20), 22-33.

Silove, D. (1999) The psychosocial effects of torture, mass human rights violations, and refugee trauma. Journal of Nervous and Mental Disease, 187, 200-207.

Summerfield, D. (2001) Asylum-seekers, refugees and mental health services in the UK. Psychiatric Bulletin, 25, 161-163.

Watters, C. (2001) Emerging paradigms in the mental health care of refugees. Social Science and Medicine, 52, 1709-1718.

\title{
Malawi
}

The country profiles section of International Psychiatry aims to inform readers of mental health experiences and experiments from around the world. We welcome potential contributors. Please contact Shekhar Saxena (email saxenas@who.int).

\section{Felix Kauye ${ }^{1}$ and Chitsanzo Mafuta ${ }^{2}$}

${ }^{1}$ Chief Government Psychiatrist, Ministry of Health, Zomba Mental Hospital, Zomba, Malawi, email felixkauye@yahoo.com ${ }^{2}$ Registrar Psychiatric Clinical Officer, Ministry of Health, Zomba Mental Hospital, Zomba, Malawi, email chitsanzomafuta@yahoo.co.uk

$\mathrm{M}$ alawi is a country with an approximate area of $118000 \mathrm{~km}^{2}$. Its population is estimated at 13 million and the gender ratio (men per hundred women) is 98 . The proportion of the population under the age of 15 years is $47 \%$ and the proportion above the age of 60 years is $5 \%$. The literacy rate is $75.5 \%$ for men and $48.7 \%$ for women (World Health Organization, 2005).

For administrative purposes, Malawi is divided into three regions, which are further divided into a total of 28 districts. The capital city is Lilongwe, which is situated in the central region, and the main means of travel between the capital and districts is by road.

The main languages used in Malawi are English and Chichewa. The largest ethnic group is Chewa and the other ethnic groups are Nyanja, Tumbuka, Yao, Nkhonde and Ngoni plus the Europeans, Indians and other foreign nationals. The largest religious groups are Christians followed by Muslims.

\section{Health indicators}

Malawi has high rates of infant and maternal mortality rates. The life expectancy at birth is 40 years for both males and females (National Statistical Office of Malawi).

\section{Health services}

There are very few doctors. Clinical officers, medical assistants and enrolled nurses comprise the backbone of Malawian healthcare, but there are shortages of these health personnel, especially in the rural areas, as people prefer to practise in urban areas.

The smallest health unit in Malawi is the 'health post', which is manned by 'health surveillance assistants' (who have 10 weeks' orientation training). Each health post serves a small number of villages. Next in the referral hierarchy is the health centre, which is usually staffed by medical assistants (who have 2 years' training) and nurses. Patients who cannot be treated at the health centre are referred to the district hospitals, which are present in all but 3 of the 28 districts. There are four general tertiary referral hospitals, distributed in all three regions of Malawi, with two in the southern region, which is the biggest.

\section{Mental health resources and services}

Zomba Mental Hospital, which is situated in the southern region, is the only government tertiary psychiatric referral hospital in Malawi. It has 333 beds and on average admits 1500 patients per year. There is a smaller psychiatric unit in the central region, in Lilongwe, with about 30 beds, and this is run as part of Kamuzu Central Hospital, which is the tertiary referral hospital in the central region. Psychiatric patients from the northern region are usually referred to a missionary hospital, St John of God in the city of Mzuzu, which has 50 in-patient beds and which runs an effective 
Table 1 Government mental health facilities at different healthcare levels

\begin{tabular}{|c|c|c|c|}
\hline Level & Facilities & Staffing & Services offered \\
\hline Tertiary & $\begin{array}{l}\text { Zomba Mental } \\
\text { Hospital }\end{array}$ & $\begin{array}{l}\text { One psychiatrist } \\
\text { One psychiatric clinical officer } \\
\text { Twenty psychiatric nurses } \\
\text { Five general clinical workers } \\
\text { Four general nursing workers } \\
\text { One occupational therapist }\end{array}$ & $\begin{array}{l}\text { Long-stay care } \\
\text { Forensic services } \\
\text { Hospital day care } \\
\text { Acute in-patient care } \\
\text { Community services } \\
\text { Rehabilitation services } \\
\text { Occupational therapy } \\
\text { Out-patient care }\end{array}$ \\
\hline $\begin{array}{l}\text { Secondary } \\
\text { (district hospitals) }\end{array}$ & $\begin{array}{l}\text { Only two have a } \\
\text { psychiatric ward }\end{array}$ & $\begin{array}{l}\text { From one to six psychiatric nurses }{ }^{1} \\
\text { Variable numbers of general clinical and nursing workers }\end{array}$ & $\begin{array}{l}\text { Acute in-patient care } \\
\text { Out-patient care } \\
\text { Community services } \\
\text { Medium-stay care } \\
\text { Outreach clinics } \\
\text { Referral to Zomba Mental Hospital }\end{array}$ \\
\hline $\begin{array}{l}\text { Primary } \\
\text { (district health centres) }\end{array}$ & $\begin{array}{l}\text { No psychiatric } \\
\text { wards }\end{array}$ & $\begin{array}{l}\text { General nurses (sometimes enrolled psychiatric nurses) } \\
\text { General health workers (clinical/medical officers) }\end{array}$ & $\begin{array}{l}\text { Minimal out-patient care } \\
\text { Referral to district hospitals }\end{array}$ \\
\hline
\end{tabular}

${ }^{1}$ Psychiatric nurses are often redeployed to general medical and surgical services, resulting in diminished delivery of mental health activities in the district hospitals.

community programme. In total there are therefore just over 400 psychiatric beds for the entire population.

The commonest reasons for admission to Zomba Mental Hospital are schizophrenia, bipolar disorders, intellectual disability, epilepsy, and substance-related and HIV-related conditions (according to hospital statistics for the year 2005). Nearly all patients admitted present with severe forms of these conditions.

Mental health services in all the districts fall under the office of the district health officer and the associated expenditure is included in the district's health budget. As with the other general tertiary hospitals, Zomba Mental Hospital has its own budget.

Public psychiatric services fall under clinical services (curative) within the Ministry of Health. The resources in terms of facilities and staffing at the different care levels are summarised in Table 1.

\section{Staffing}

There is only one psychiatrist for the entire population of Malawi, but since he is based in Zomba, the old capital city, the psychiatrist:population ratio is 0 for the rest of the country.

There are no professional social workers and only one occupational therapist, at Zomba Mental Hospital. There are two clinical psychologists attached to the College of Medicine in Malawi, who teach medical students; they do not do any clinical work in the psychiatric hospitals.

The district psychiatric nurses do weekly outreach clinics, visiting different health centres and health posts within their districts; the management team from Zomba Mental Hospital visits each district twice a year to monitor mental health activities throughout the country.

\section{World Mental Health Day}

World Mental Health Day is celebrated publicly every year in a selected district. Posters, T-shirts and leaflets explaining mental health issues are distributed to the public for free at the chosen venue. The public's response to this has always been very encouraging.

\section{Mental health policy and legislation}

The old 2000-04 policy is still being used while it is awaiting review. This policy includes the integration of psychiatric services into the primary healthcare system, the appointment of a national mental health coordinator at the Ministry of Health's headquarters and a human resources development plan.

The Mental Treatment Act was enacted in 1959 and amended in 1968. A Mental Health Bill is awaiting review by stakeholders and later parliamentary amendment; it is anticipated that it will be passed in 2007. It compares well with legislation in countries such as South Africa and Kenya, and includes the formation of a mental health review board, which will monitor the care and treatment of psychiatric patients in hospital. It covers areas such as admissions, the rights of inpatients and the safekeeping of patients' property.

\section{Training}

\section{Undergraduate medical students}

There is one medical school, the Malawi College of Medicine, which is part of the University of Malawi, in Blantyre. As part of their MBBS course, students in the third year have 2 weeks of psychiatry theory and in the fourth year they undergo a 5week rotation in theory and clinical work.

\section{Other health workers}

The two main health sciences colleges offer training of paramedical staff - the clinical officers, medical assistants and enrolled nurses. Clinical officers can go for further training in specific areas and become psychiatric clinical officers, orthopaedic clinical officers and so on. Plans are being finalised to train district primary health workers in the management of common psychiatric disorders. Currently, most primary health workers lack skills in the assessment and management of psychiatric patients and end up referring all those they come across. 


\section{Postgraduate specialisation}

The College of Medicine at the University of Malawi has offered postgraduate training only since 2005 in certain specialties, in conjunction with certain universities in South Africa. This does not include psychiatry, so all psychiatric training at present has to be done outside Malawi.

\section{Psychiatric nurses}

The St John of God College of Health Sciences provides a degree in psychiatric nursing for registered state nurses with a minimum of a university diploma in nursing, and the Malawi College of Health Sciences provides a certificate course in psychiatry for enrolled nurses.

\section{Research}

Mental health in Malawi has been the subject of several research projects. These have included studies in psychoactive substances, the teaching of psychiatry in the colleges and attributions for admissions to Zomba Mental Hospital (MacLachlan et al, 1995). More studies are under way or being developed by Zomba Mental Hospital on, for example:

O community attitudes to and knowledge of mental illness

$O$ the prevalence of HIV and neurosyphilis among inpatients

O district mental health activities in southern Malawi, including what proportions of the district budgets are allocated to mental health

O common causes of relapse and readmission in patients with schizophrenia

O pathways to care for psychiatric patients

O neuropsychological sequalae of cerebral malaria.

At the St John of God Hospital a randomised controlled trial of carer education in schizophrenia and bipolar disorders is under way.

In general, there is not much information on mental health in the Malawian context and this provides opportunities and challenges for research.

\section{Professional organisations}

In the past there was a Mental Health Association of Malawi, but it stopped functioning, for unknown reasons, around 1999. At present, a 'core group' is being formed, comprising: the psychiatrist at Zomba Mental Hospital; the clinical psychologist at the Malawi College of Medicine; the chief nursing officer at Zomba Mental Hospital; and the psychiatric clinical officer at the St John of God Hospital. The main goal of this core group is to develop the preliminary constitution of a new professional association and to recruit members. Some of the functions of the association will be:

$O$ to deal with challenges in mental health

O to act as an advisory body to the Medical Council of

Malawi on the registration of mental health professionals

O to develop, review and conduct policy for mental health professionals.

There are at present no non-governmental organisations operating in the mental health field in Malawi.

\section{Challenges}

Notable problems include a critical shortage of trained staff and frequent shortages of drugs owing to procurement problems. The referral system is not very good; neither is follow-up care, as most district psychiatric services seem to be insufficiently well developed.

\section{References}

MacLachlan, M., Nyirenda, T. \& Nyando C. (1995) Attributions for admission to Zomba Mental Hospital: implications for the development of mental health services in Malawi. International Journal of Psychiatry, 41, 79-87.

National Statistical Office of Malawi. See http://www.nso.malawi.net/ data_on_line/demography/census_98/mortality_measures.htm. Last accessed 23 October 2006.

World Health Organization (2005) Mental Health Atlas 2005. See http:// www.who.int/globalatlas/predefinedReports/MentalHealth/Files/MW Mental_Health_Profile.pdf. Last accessed 23 October 2006.

\section{Mental health and psychiatry in Thailand}

\section{Pichet Udomratn MD}

Department of Psychiatry, Faculty of Medicine, Prince of Songkla University, Hat Yai, Songkhla, 90110, Thailand, email upichet@medicine.psu.ac.th

\footnotetext{
hailand is located in Southeast Asia and covers an area of $513115 \mathrm{~km}^{2}$. In 2006 its population was approximately 64 million. The major nationality is Thai. About $80 \%$ of the total population live in rural areas. The country is composed of 76 provinces, divided into a total of 94 districts and 7159 sub-districts.
}

\section{Prevalence of mental illnesses}

The latest data concerning the prevalence of mental disorders in Thailand were obtained from a national survey conducted in 2003. The survey was a two-step cross-sectional community survey using AUDIT (Alcohol Use Disorders 